\title{
Complex Regional Pain Syndrome I
}

National Cancer Institute

\section{Source}

National Cancer Institute. Complex Regional Pain Syndrome I. NCI Thesaurus. Code C85042.

A neurologic condition characterized by burning pain, tenderness, swelling, and changes in the skin color and temperature of a body part or extremity that has no identifiable nerve injury; most pediatric patients present with this form. 